\title{
Direito Social em favor dos pobres: perspectivas da adoção de meios alternativos de solução de controvérsias nos conflitos de direito à saúde
}

Social rights in favor of the poor: perspectives for the use of alternative dispute resolution in health law conflicts

\section{Maria Gabriela Araújo Diniz}

Advogada. Doutoranda em Direitos Humanos. Referência Técnica em Direito Sanitário da Escola de Saúde Pública do Estado de Minas Gerais. Belo Horizonte, Brasil.

Resumo: Partindo da crítica de que a abordagem positivista do Direito mantém as estruturas de domínio e poder econômico, e da crítica de que os direitos sociais são apropriados pelas classes mais privilegiadas em prejuízo das classes mais vulneráveis, analisa-se a questão da judicialização da saúde como expressão de um direito social contra os pobres e da concentração de poder promovida pelo Direito. A apreciação pelo Judiciário das demandas envolvendo direitos sociais - como o direito à saúde - mostra-se pautada por parâmetros inadequados, pois destinados à solução de conflitos de direitos individuais, abrindo, até mesmo, margem para o questionamento se os direitos sociais teriam "justiciabilidade". Tendo em mente essa inadequação, aborda-se a adoção de meios alternativos de resolução de controvérsias para a solução de demandas de saúde como uma alternativa viável à judicialização da saúde, e que apresenta menor potencial de perturbação da organização das políticas públicas de saúde e uma promessa de desestabilização das estruturas de domínio econômico.

Palavras-chave: Direito à Saúde; Judicialização da Saúde; meios alternativos de solução de controvérsias.

Key-words: Health Law; Judicialization of health; Alternative Dispute Resolution;

1 Crítica ao positivismo jurídico: concentração de poder e assimetria de informação

No artigo Novo estruturalismo jurídico: uma alternativa para o direito?, Calixto Salomão Filho (2012) afirma que a abordagem positivista do direito confere a essa ciência um caráter de manutenção das estruturas sociais e econômicas. Sob esse ponto de vista, o 
direito foi separado da moral, e o direito foi tomado como um sistema fechado em si mesmo, cujo fundamento se encontra em sua própria lógica interna.

A consequência desse fechamento é que o direito torna-se alheio às questões sociais e, dessa forma, repete uma lógica cujo resultado não é outro senão a manutenção das estruturas de domínio e poder econômico. A atuação do direito na diminuição das injustiças sociais restringe-se a meras compensações que, por sua vez, são incapazes de promover alterações estruturais (Salomão Filho, 2012):

é difícil conseguir através do direito a transformação econômica e social, pois compensações serão sempre insuficientes para fazer frente às desigualdades continuamente criadas em múltiplas esferas do sistema econômico, baseado que é em estruturas de poder econômico extremamente concentrado. (Salomão Filho, 2012, p. 539).

Fazendo uma analogia com a teoria de Akerlof (1970) para o mercado de carros usados $^{1}$, podemos afirmar que a manutenção das estruturas de poder econômico pelo direito assenta-se em uma assimetria de informações, pela qual os grupos sociais dominantes retêm o conhecimento acerca do sistema jurídico e o exploram para aumentar cada vez mais seus privilégios (Gouvêa, 2013). Desta forma, a menos que se promova uma intervenção combatendo tal assimetria, o direito continuará tendente à concentração de poder.

No mesmo sentido da crítica do direito como concentrador de poder, Carlos Portugal Gouvêa (2013) argumenta que, no Brasil, os direitos econômicos e sociais foram apropriados por grupos econômicos privilegiados, rompendo, portanto, com sua proposta de proteção dos grupos sociais vulneráveis. Segundo ele, esse resultado decorre de dois fatores: o patrimonialismo, que consiste na confusão entre recursos públicos e privados com consequente concentração de recursos econômicos e poder político nas mãos de poucos (Gouvêa, 2013), e o fato de que o Judiciário confere maior proteção aos direitos dos grupos sociais já privilegiados em detrimento das classes menos favorecidas (Gouvêa, 2013). Uma das razões apontadas para isso é que o Judiciário, ao decidir casos envolvendo direitos sociais e econômicos, usa a mesma lógica utilizada para casos de direitos individuais.

\footnotetext{
${ }^{1}$ Segundo Akerlof (1970), no mercado de carros usados (conhecidos como limões), somente os vendedores possuem informações sobre a qualidade dos carros, ocorre uma assimetria de informações. Como os carros bons e os ruins seriam vendidos pelo mesmo preço, pois seria impossível para o comprador, no momento da compra, distinguir os carros bons dos ruins, ocorre uma tendência a que os carros bons sejam retirados do mercado, o que leva a sua restrição. E, sem que ocorra uma intervenção sobre esse mercado, ele tende à concentração de poder nas mãos dos vendedores.
} 
Como mencionado por David Kennedy (2002), existe, no movimento dos direitos humanos, um verdadeiro fetiche que vê o juiz como um instrumento do direito, acreditando exageradamente, portanto, no aparato do Judiciário e na própria figura do juiz como esfera de proteção dos direitos. Para Kennedy (2002), essa proteção é prejudicada em parte porque o Judiciário é também palco de disputas políticas; além disso, prejuízo maior ocorre no que tange os direitos sociais, em virtude da inadequação de usar para esses direitos a mesma lógica usada para os direitos individuais.

Virgílio Afonso da Silva (2008) ressalta, nessa direção, o erro de se conceder o mesmo tratamento a direitos sociais e a direitos individuais. Consoante ele, os direitos sociais demandam um tratamento diverso do "raciocínio jurídico-formal" (Silva, 2008, p. 590), uma vez que envolvem a definição de políticas públicas mediante as quais se decide onde serão aplicados os escassos recursos públicos (Silva, 2008). Ademais, esses direitos possuem uma esfera coletiva que é desconsiderada pelo Judiciário quando os trata segundo o raciocínio jurídico-formal, ou seja, segundo a lógica dos direitos individuais (Silva, 2008).

Nos conflitos envolvendo direitos individuais, o que está em jogo são conflitos retributivos ou bipolares (Borges, Ugá, 2009), em que uma parte ganha e outra parte perde algo. Nos conflitos de direitos sociais, entretanto, trata-se de conflitos distributivos (Borges, Ugá, 2009), não envolvem somente duas partes em que uma delas é sagrada vencedora, mas implicam ganho ou perda para a sociedade como um todo (Borges, Ugá, 2009).

Contribuindo com esse cenário, cabe, mais uma vez, trazer a noção da assimetria de informação (Akerlof, 1970): os grupos privilegiados conhecem seus direitos e possuem condições de arcar com os custos de levar suas demandas ao Judiciário, incluindo aqueles de uma boa representação legal. Os grupos desfavorecidos, ao contrário, muitas vezes desconhecem seus direitos e, mesmo quando os conhecem, sentem-se intimidados pelo funcionamento do Judiciário, além de não poderem suportar os custos de uma batalha judicial (Resnik, 1995).

Nesse sentido, ao conceder direitos sociais individualmente, o Judiciário provoca 0 desvio de recursos, inicialmente destinados a políticas públicas para atender a uma coletividade, para uma parcela limitada da população (Silva, 2008); as sentenças, assim, beneficiam os grupos privilegiados que recorrem a esse poder e acabam por prejudicar aqueles que mais precisam da proteção desses direitos (Gouvêa, 2013).

Percebe-se, aqui, a acuidade da crítica feita por Salomão Filho (2012): o Judiciário, na proteção dos direitos econômicos e sociais, garante maior proteção aos já privilegiados e 
descuida dos menos favorecidos, mantendo, assim, a desigualdade social e garantindo sobrevida às estruturas de concentração do poder e do domínio econômico. Carlos Portugal Gouvêa (2013) chamou essa distorção de "direitos sociais contra os pobres" (Gouvêa, 2013).

Tal distorção pode ser bem ilustrada pela realidade do direito à saúde, sobretudo quando levamos em conta o fenômeno da judicialização da saúde, como pretendemos comprovar mais adiante.

\section{Direito à saúde e Judicialização da Saúde}

Até a década de 1980, o direito à saúde, no Brasil, era assegurado apenas aos trabalhadores urbanos, com vínculos trabalhistas formais, que gozavam de um seguro de saúde cujo financiamento derivava de descontos em seus salários (Elias, 2004). Com a promulgação da Constituição de 1988, o direito à saúde foi inscrito como um direito fundamental, de acesso amplo, e que deveria ser prestado - e, em parte, financiado - pelo Estado.

O direito à saúde foi, então, incluído no rol dos direitos sociais. E dessa classificação decorrem duas características (Ramos, 2005): por um lado, os direitos sociais possuem um caráter objetivo, pois integram o "ordenamento jurídico objetivo da coletividade" (Ramos, 2005, p. 148), exigindo do Estado a organização da rede de prestação dos serviços de saúde (Aith, 2010), e, por outro lado, dispõem de um caráter subjetivo, que garante um direito individual e o respectivo dever do Estado de assegurá-lo. Dizer que o direito à saúde é um direito social significa, pois, que o indivíduo pode exigir do Estado prestações positivas de ações e serviços de saúde.

Da possibilidade de imposição do cumprimento pelo Estado da prestação de ações e serviços de prevenção e tratamento de doenças, abre-se, consequentemente, a possibilidade de que os indivíduos acionem o Poder Judiciário para, por meio de decisões judiciais, obter as prestações de que necessitam.

Desde a década de 90, na esteira de demandas judiciais por medicamentos e procedimentos efetuados por portadores de HIV/aids (Ventura et al., 2010), fixou-se a interpretação de que o direito fundamental à saúde consiste em norma constitucional de eficácia plena (Machado, 2008), impondo à Administração Pública "um dever políticoconstitucional impostergável” (Ramos, 2005, p. 159). Desde então, o Judiciário apresenta uma forte tendência de deferimento dos pedidos individuais por ações e serviços de saúde. 
Essa resposta criou um ambiente favorável para o crescimento exponencial das demandas judiciais em saúde, iniciando "a inclusão do recurso judicial no 'itinerário terapêutico' de milhares de cidadãos" (Ventura et al., 2010, p. 78). Tal fenômeno é convencionalmente chamado judicialização da saúde ${ }^{2}$.

A judicialização da saúde apresenta um aspecto positivo, indicando maior participação da população por meio da exigência de cumprimento de seus direitos, ou, nos dizeres de Sílvia Marques, representa o "exercício efetivo de cidadania" (Marques, 2008, p. 65). Por outro lado, a judicialização interfere na execução das políticas públicas de saúde, pressionando os gestores para atender ao numeroso volume de ordens judiciais.

A proposição de ações judiciais faz parte da efetividade do direito à saúde, uma vez que cabe ao Poder Judiciário assegurar o respeito a esse direito, apreciando as lesões ou ameaças de lesão ao direito à saúde levadas a seu conhecimento. Quando o Judiciário impõe a execução de uma ação ou a prestação de serviço de saúde constante da política pública, esse poder está exercendo sua função primordial no âmbito do direito sanitário, qual seja a de zelar para que as políticas públicas sejam executadas, assegurando a efetividade do direito à saúde (Aith, 2010).

O problema aparece quando a judicialização torna-se aleatória e excessiva, ferindo os princípios norteadores do SUS, e quando a decisão judicial desconsidera a existência de políticas públicas de saúde relacionadas com os pedidos por ele apreciados.

\section{Direito à saúde: "direito social contra os pobres"}

O artigo $7^{\circ}$ da Lei $n^{\circ}$ 8.080/90, que, juntamente com a Lei 8.142/90, compõem a Lei Orgânica da Saúde, enumera os princípios que devem reger o SUS. Dentre eles, destacamos os princípios da igualdade de acesso e o princípio da integralidade da assistência, aos quais se adiciona o princípio da equidade.

O princípio da integralidade define-se como "o conjunto articulado e contínuo das ações e serviços preventivos e curativos, individuais e coletivos, exigidos para cada caso em todos os níveis de complexidade do sistema" (Brasil, 1990). Lenir Santos (2005) enfatiza que a integralidade da assistência demanda a atuação conjunta dos entes federativos, agindo conforme planos de saúde pactuados, principalmente, no âmbito da Comissão Intergestores

${ }^{2} \mathrm{O}$ termo judicialização é utilizado neste contexto, significando a interferência do poder Judiciário em questões de competência do Executivo e do Legislativo (Chieffi; Barata, 2009). 
Tripartite (CIT) e da Comissão Intergestores Bipartite (CIB) (Aith 2010). Lembrando-se que, na definição das políticas públicas que comporão os planos e visto que os recursos disponíveis para aplicação na saúde são escassos, os gestores devem levar em conta critérios epidemiológicos, técnicos e científicos, bem como avaliações de custo efetividade, para determinar, em razão das características da população a que destinam as políticas e dos objetivos pretendidos, quais os tratamentos, os medicamentos, as ações e os serviços que terão prioridade no fornecimento (Vieira, 2008; Chieffi, Barata, 2009).

Conforme Fabíola Sulpino Vieira (2008), existe uma diferença entre o que pretendido pelo princípio da integralidade no SUS e o que o Judiciário entende desse princípio. Enquanto no SUS integralidade significa "empregar os meios necessários para a efetivação do cuidado" (Vieira, 2008, p. 2) e "dispor tipos diferentes desses meios segundo o grau de complexidade da atenção à saúde" (Vieira, 2008, p. 2-3), para o Judiciário esse princípio significa deferir todas as demandas individuais a despeito da existência de políticas públicas (Vieira, 2008).

Lenir Santos (2005) destaca, nesse sentido, que é contrário à integralidade que o indivíduo pleiteie todo e qualquer tratamento que deseje e que os profissionais de saúde tenham total liberdade de prescrição. Segundo a autora, isso seria transformar a assistência em aleatória, e tal aleatoriedade deve ser combatida por meio do respeito ao que pactuado nos referidos planos de saúde:

O direito à integralidade da assistência terapêutica não pode ser aleatório e ficar sob a mais total independência reivindicatória do cidadão e da liberdade dos profissionais de saúde indicarem procedimentos, exames, tecnologias não incorporadas no sistema, devendo a conduta profissional pautar-se por protocolos, regulamentos técnicos e outros parâmetros técnico-científico-biológico [sic]. (Santos, 2005).

Porém, o que verificamos na judicialização da saúde é justamente essa aleatoriedade, representativa de uma visão mercadológica da saúde, segundo a qual essa é transformada em um bem de consumo, gerado por uma lógica do desejo e não da necessidade (Santos, 2012; Vieira, 2008). Equiparar a saúde a um bem de consumo significa negá-la como direito, uma vez que o acesso, no âmbito do consumo, passa a reger-se por critérios de renda: quem pode pagar, pode usufruir.

Esse prejuízo causado pela judicialização é, ainda, reforçado pelo fato de que parte dos pedidos se relaciona a medicamentos, procedimentos e exames caros e é promovida por advogados particulares, ou seja, configuram demandas representativas dos "desejos" de uma classe que não depende, necessariamente, da proteção dos direitos sociais (Vieira, 2008). 
Nesse aspecto, a judicialização da saúde fere o princípio da igualdade de acesso, criando obstáculos à efetividade do direito à saúde daqueles indivíduos que não podem arcar com os custos de um advogado (Chieffi, Barata, 2009).

Destarte, quando esses pedidos são deferidos, provocam a realocação dos recursos destinados a ações e serviços que assegurariam o básico à população em risco e que podem deixar de ser prestados. Acerca dessa distorção, é paradigmática a lição de Lenir Santos:

Não se pode garantir o direito de um cidadão de se tratar no exterior enquanto o sistema público não conseguir dar conta de evitar a morte de bebes [sic] indígenas por desnutrição ou por falta de UTI, sob pena de a igualdade pretendida no SUS não ser equânime. Não é justo, não é razoável organizar um sistema que possibilita, de um lado, pacientes tratando-se no exterior e de outro, gestantes morrendo nas salas de parto por falta de atendimento adequado. (Santos, 2005).

Toda ação e serviço de saúde possui um preço (Santos, 2012), de maneira que as sentenças que deferem os pedidos na área da saúde comprometem o orçamento destinado à prestação de outro serviço. Em certa medida, implicam a transferência de recursos destinados à satisfação da necessidade de muitos - usualmente os indivíduos com maior vulnerabilidade social - para o atendimento do interesse de poucos - os de menor índice de vulnerabilidade social (Chieffi, Barata, 2009). Neste aspecto, a judicialização vai de encontro com o princípio da equidade, que significa conceder maior proteção aos que dela mais precisam (Chieffi, Barata, 2009). Muito ao contrário, o que se verifica é que aqueles que não se encontram em situação de risco é que são beneficiados, aumentando a exclusão dos demais.

Assim, o deferimento de prestações de saúde pelo Judiciário realiza o direito à saúde para o indivíduo, contudo, pode colocar em risco a possibilidade de realização dessa mesma prestação para a coletividade. De modo geral, a judicialização da saúde compromete o ideal da universalidade, da igualdade de atendimento e da equidade, já que, notadamente, privilegia aqueles que podem recorrer ao sistema judicial; beneficia, portanto, os grupos com maior poder de reivindicação (Ventura et al., 2010; Salomão Filho, 2012; Gouvêa, 2013).

E, finalmente, conforme disposto no artigo 198 da Constituição Federal, a organização da rede de ações e serviços de saúde deve pautar-se pela participação da comunidade, realizando o ideal da participação democrática (Aith, 2010). Assim, além de provocar a realocação de recursos de uma atividade para outra, existe o risco de as decisões judiciais desrespeitarem o que foi acordado nas instâncias de participação democrática, violando, também, o princípio da participação da sociedade na organização do Sistema Único de Saúde. 
O Judiciário, ao resolver o caso levado a sua análise, deve tentar resolver esse caso concreto à luz dos objetivos pretendidos pelas políticas públicas de saúde, em outras palavras, deve tentar compatibilizar a justiça no caso concreto com a justiça distributiva expressa nas políticas públicas de saúde (Marques, 2008). Porém, nem sempre o Judiciário segue tais políticas, (Marques, Dallari, 2007), sobretudo porque, conforme mencionado por Sílvia Marques (2008), essas políticas não possuem uma sistematização.

Pelo que exposto, pode-se dizer que recorrer ao Judiciário para assegurar a efetividade do direito à saúde, em detrimento do que previsto nas políticas públicas de saúde, contraria os princípios informadores do SUS e torna o direito à saúde um direito social contra os pobres, pois a judicialização da saúde prejudica a efetividade do direito à saúde dos menos favorecidos ao mesmo tempo em que beneficia aqueles que já são privilegiados.

\section{Meios alternativos de resolução de controvérsias em conflitos de direito à saúde}

Como já apresentado, existe uma inadequação entre tratar os direitos sociais pelo mesmo viés em que são abordados os direitos individuais. Nesse mesmo diapasão, Céline Fercot (2011) discute se os direitos sociais teriam "justiciabilidade" (Fercot, 2011, p. 229), ou seja, se "possuem a qualidade daquilo que pode ser examinado pelos juízes" (Fercot, 2011, p. 229).

Nessa discussão, ela torna claro que há duas correntes diferentes: uma que nega a justiciabilidade dos direitos sociais, pois os juízes não poderiam realizar as "promessas jurídicas" que implicam tais direitos, pois, para tanto, os juízes invadiriam domínios fora de sua competência (Fercot, 2011), e outra corrente que, contrariamente, defende a justiciabilidade dos direitos sociais com base no argumento que, sendo direitos fundamentais, podem ser determinados pelo judiciário nos casos de ausência de concretização pelo legislativo (Fercot, 2011).

Ao lado desse questionamento, persiste a constatação da inadequação do tratamento conferido pela judicialização dos direitos sociais, o que impõe a busca de uma abordagem alternativa e de meios mais adequados para a solução das questões envolvendo aqueles direitos.

Nesse ponto nos interessam os meios de resolução alternativa de disputas (ADR, sigla em inglês para Alternative Dispute Resolution) voltados para a solução de conflitos em direito à saúde, como os projetos implementados pela Defensoria Pública do Estado de São 
Paulo, o Comitê Interinstitucional de Resolução Administrativa de Demandas da Saúde (CIRADS) no Estado do Rio Grande do Norte, o projeto "Mediação Sanitária: direito, saúde e cidadania" do Ministério Público do Estado de Minas Gerais, e a Câmara Permanente Distrital de Mediação de Saúde (CAMEDIS) no Distrito Federal. De modo geral, essas iniciativas de ADR consistem na formação de comitês em que se reúnem representantes das Secretarias de Saúde e da Defensoria Pública, seja estadual ou da União, e seus objetivos são os de facilitar a solução de pedidos de ações ou serviços de saúde, por meio de tratativas entre os representantes dos órgãos e os usuários do SUS, e sem que se faça necessário ajuizar uma ação.

Os ADR surgiram, no direito norte-americano, como consequência do "movimento de livre acesso à justiça", que advogava pelo acesso de todos a um meio que Ihes permitisse uma solução eficaz para seus conflitos e, em busca desse objetivo, propôs meios alternativos aos tribunais (Vilar, 2011). Os ADR ofereceriam "múltiplas portas" de acesso à justiça e supririam a demanda nas situações em que a "porta" da adjudicação fosse percebida como fechada (Resnik, 1995). Esses mecanismos, resumidamente, consistem em práticas e técnicas que permitem a solução de problemas fora dos tribunais (Mnookin, 1998) e seus exemplos mais comuns são a conciliação, a arbitragem e a mediação.

Os defensores dos meios alternativos de resolução de disputas argumentam que tais meios, comparados à adjudicação, provêm soluções mais rápidas e com custos mais reduzidos (Resnik, 1995), que as soluções propostas são mais adequadas à satisfação dos interesses das partes já que foram construídas por elas mesmas e não impostas por um terceiro, e que, por esse motivo, possuem maior grau de cumprimento (compliance) (Mnookin, 1998; Resnik, 1995). Além disso, enfatiza-se que os ADR são meios mais eficientes para a solução de controvérsias, uma vez que sua principal orientação é no sentido da composição dos interesses para a realização de acordos (Resnik, 1995).

Segundo Kazuo Watanabe (2011), ao lado da redução do número de processos judiciais, o que os mecanismos alternativos de resolução de conflitos trazem de mais relevante é a possibilidade de que as partes cheguem a uma solução que satisfaça seus interesses e que também preserve seu relacionamento (Watanabe, 2011). Ele destaca, nesse sentido, a necessidade de alteração do paradigma de solução baseado na adjudicação - denominado "cultura da sentença" 
(Watanabe, 2011, p. 4) - pela "cultura da pacificação" (Watanabe, 2011, p. 9), em que a solução acordada prima pela preservação das relações entre os participantes com redução dos conflitos residuais.

Os meios alternativos de solução de conflitos respondem, notadamente, a uma necessidade de celeridade nas decisões, o que, no campo da saúde, em que a própria vida do indivíduo pode estar em risco, representa um aspecto altamente positivo.

Em adição, os ADR são defendidos por serem meios menos caros que a adjudicação e essa redução de custos, ainda mais porque dispensável o acompanhamento por advogado, importa a ampliação do acesso à justiça do grupo social mais vulnerável. Neste aspecto, a disponibilização de meios alternativos de solução de controvérsia oferece um palco para a defesa dos direitos da classe que mais necessita da proteção da justiça.

Os ADR destacam-se, igualmente, por promoverem o diálogo entre o usuário do SUS, o gestor de saúde e os demais atores do direito sanitário. Essa comunicação permite que sejam trazidas à tona as políticas públicas de saúde, quando existentes, e que a solução alcançada seja pautada por essas políticas. Da mesma forma, quando inexistentes políticas públicas para o assunto específico, os ADR permitem que o representante da gestão possa transacionar com o usuário de saúde para chegar a um acordo que, comparado com uma decisão judicial, minimize o impacto sobre os recursos públicos.

Nesse sentido, os meios alternativos de solução de disputas promovem a troca de informações entre os participantes, o que contribuiria, ao menos no caso concreto, para a diminuição da assimetria de informação que tende à concentração de poder nas mãos das classes mais privilegiadas. O diálogo entre os participantes, incrementado pelo fato de que 0 acordo depende da participação e aquiescência de todos os envolvidos, tenderia, ao longo dos procedimentos, a reduzir a desigualdade de informações entre os participantes.

Os ADR, ainda, permitem mitigar o raciocínio jurídico-formal pelo qual o Judiciário cuida das demandas de direitos individuais e que conflita com os fins dos direitos sociais, pois permite a redução do impacto negativo para a coletividade. Aqui, a lógica que prevalece é a de que o resultado satisfaça aos interesses de todos os participantes, de forma que todos se sintam vencedores, diferentemente da decisão judicial pela qual uma parte sai vencedora e outra perdedora. As tratativas para o acordo, por exemplo, tornam possível que o pedido de um medicamento caro seja substituído por seu equivalente genérico, reduzindo o impacto sobre o orçamento. Assim, a adoção de meios alternativos de solução de controvérsias nos conflitos de saúde permite que os objetivos distributivos desse direito social sejam 
enfatizados, ao contrário do que acontece com as decisões judiciais cujo efeito é retributivo e potencialmente lesivo aos interesses da coletividade (Borges, Ugá, 2010).

Ademais, os ADR por incluírem o usuário na formação da solução e, sobretudo quando envolvem a participação de representantes dos conselhos estaduais e municipais de saúde, tal como acontece no projeto realizado no Estado de Minas Gerais, supriria, em parte, a necessidade de participação popular na execução das políticas de saúde, princípio norteador do SUS que resta violado quando a prestação de uma ação ou de um serviço de saúde é imposta pelo Judiciário em detrimento do que pactuado nas CIT e CIB.

Contudo, é preciso destacar que os ADR sofrem duras críticas, as quais precisam ser também consideradas quando de sua aplicação nos conflitos de direito sanitário. Owen Fiss (1984), por exemplo, discorda que um acordo deva ser preferível à adjudicação, pois, segundo ele, no caso de haver desigualdade de recursos e de informações entre os participantes, existirá a possibilidade de que a parte mais forte imponha um acordo desvantajoso para a parte mais pobre. Sob essa perspectiva, os ADR repetem a mesma lógica de concentração do poder que a abordagem positivista carrega.

\section{Considerações finais}

Não se está advogando, aqui, a adoção de meios alternativos de solução de controvérsias como panaceia para os problemas da gestão em saúde, tampouco se espera que os ADR, per se, consigam provocar a alteração das estruturas sociais tendentes à concentração de poder. É preciso, não obstante, cuidar para que essa concentração de poder não seja aplicada nos procedimentos do ADR, impondo um acordo contrário aos interesses do participante mais vulnerável.

Entretanto, as iniciativas de uso de meios alternativos de resolução de disputas em conflitos de direito à saúde vem se mostrando como alternativas salutares à proposição de ações judiciais, permitindo que a decisão para um caso individual seja tomada levando-se em consideração, e não em detrimento, do que planejado para a coletividade. As trocas de informação realizadas durante os procedimentos dos ADR acrescentam um aspecto positivo já que contribuem para a redução da assimetria de informação entre os participantes.

A solução dos casos pela via da solução extrajudicial, visto o que brevemente apresentado neste trabalho, confere um resultado mais eficiente tanto do ponto de vista do indivíduo como sob a perspectiva dos objetivos do direito social à saúde. 


\section{Referências}

AITH, Fernando. A saúde como direito de todos e dever do estado: o papel dos poderes executivo, legislativo e judiciário na efetivação do direito à saúde no Brasil. In: AlTH, Fernando et al (org.). Direito sanitário: saúde e direito, um diálogo possível. Belo Horizonte : ESP-MG, 2010, p. 73-105.

AKERLOF, George A. The market for "lemons": quality uncertainty and the market mechanism. The Quarterly Journal of Economics, 84(3): 488-500, Aug. 1970

BORGES, Danielle da Costa Leite; UGÁ, Maria Alicia Dominguez. Conflitos e impasses da judicialização na obtenção de medicamentos: as decisões de $1^{\text {a }}$ instância nas ações individuais contra o Estado do Rio de Janeiro, Brasil, em 2005. Cadernos de Saúde Pública, Rio de Janeiro, 26(1):59-69, jan. 2010

BRASIL. Constituição (1988). Constituição da República Federativa do Brasil. [on line] Disponível

em:

http://www.planalto.gov.br/ccivil 03/constituicao/ConstituicaoCompilado.htm Acesso em: 13 out. 2012.

BRASIL. Lei $n^{\circ}$ 8.080, de 19 de setembro de 1990. Dispõe sobre as condições para a promoção, proteção e recuperação da saúde, a organização e o funcionamento dos serviços correspondentes e dá outras providências. [on line] Disponível em: http://portal.saude.gov.br/portal/arquivos/pdf/lei8080.pdf . Acesso em 03 jun.2013.

BRASIL. Lei no 8.142 de 28 de dezembro de 1990. Dispõe sobre a participação da comunidade na gestão do Sistema Único de Saúde (SUS) e sobre as transferências intergovernamentais de recursos financeiros na área da saúde e dá outras providências. [on line] Disponível em: http://www.planalto.gov.br/ccivil 03/leis/L8142.htm . Acesso em 13 out. 2012.

CHIEFFI, Ana Luiza; BARATA, Rita Barradas. Judicialização da política pública de assistência farmacêutica e equidade. Caderno de Saúde Pública, Rio de Janeiro, 25(8):1839-1849, ago. 2008.

CIARLINI, Direito à saúde e respeito à Constituição. In: SANTOS, Nelson Rodrigues dos; AMARANTE, Paulo Duarte de Carvalho (org). Gestão pública e relação público privado na saúde. Rio de Janeiro : CEBES, 2010. p. 87-100.

CONSELHO NACIONAL DE JUSTIÇA. Reunião do II Fórum do Judiciário para a Saúde. Recomendações do II Fórum Nacional de Saúde. Dezembro de 2011. [on line] http://www.cnj.jus.br/images/programas/forumdasaude/recomendacoes do II encontr o de saude.pdf. Acesso em 03 jun. 2013.

DEFENSORIA PÚBLICA DA UNIÃO. CIRADS. O que é o CIRADS? 28 de agosto de $2010 . \quad$ [on line] Disponível em: http://www.dpu.gov.br/index.php?option=com content\&view=article\&id=2335\&ltemid= 303. Acesso em 16 jun. 2013.

ELIAS, Paulo Eduardo. Estado e saúde: os desafios do Brasil contemporâneo. São Paulo em Perspectiva,18(3):41-46, 2004.

FERCOT, Céline. La justiciabilité des droits sociaux em Allemagne et Suisse: des réticences progressivement surmontées. Revue Internationale de Droit Comparé, 63(2):225-256, avr./jui. 2011.

FISS, Owen M. Against Settlement. The Yale Law Journal, 93(6):1073-1090, May 
1984.

GOUVÊA, Carlos Portugal. Social rights against the poor. Vienna Journal on International Constitutional Law, 7, 2013 [no prelo]. [on line] Disponível em: http://ssrn.com/abstract=2219890. Acesso em 08 maio 2013.

INTITUTO INNOVARE. Obtenção de medicamentos extrajudicialmente. [on line] Disponível em: http://www.premioinnovare.com.br/praticas/obtencao-de-medicamentosextrajudicialmente/ . Acesso em 16 jun. 2013.

KENNEDY, David. The international human rights movement: part of the problem? Harvard Human Rights Journal, 15:101-125, 2002.

MACHADO, Felipe Rangel de Souza. Contribuições ao debate da judicialização da saúde no Brasil. Revista de Direito Sanitário, 9(2):73-91, jul./out. 2008.

MARQUES, Sílvia Badim. Apresentação: judicialização do direito à saúde. Revista de Direito Sanitário, 9(2):65-772, jul./out. 2008.

MARQUES, Sílvia Badim; DALLARI, Sueli Gandolfi. Garantia do direito social à assistência farmacêutica no Estado de São Paulo. Revista de Saúde Pública, 41(1): 101-107, 2007.

MINISTÉRIO PÚBLICO DE MINAS GERAIS. Mediação Sanitária: direito, saúde e cidadania. Belo Horizonte, brochura, 2012.

MNOOKIN, Robert H.. Alternative Dispute Resolution. The New Palgrave Dictionary of Economics and the Law, 1998. [on line] Disponível em: http://ssrn.com/abstract=117253 . Acesso em 16 jun. 2013.

RAMOS, Marcelene Carvalho da Silva. O direito fundamental à saúde na perspectiva da Constituição Federal. A \& C: Revista de Direito Administrativo e Constitucional. Belo Horizonte, 5(22):147-165, out. 2005.

RESNIK, Judith. Many Doors? Closing Doors? Alternative Dispute Resolution and Adjudication. The Ohio State Journal on Dispute Resolution, 10(2):211-265, 1995.

SALOMÃO FILHO, Calixto. Novo estruturalismo jurídico: uma alternativa para o direito? Revista dos Tribunais, 926:533-547, dez. 2012.

SANTOS, Lenir. Direito à saúde x consumo de saúde. In: OLIVEIRA, Neilton Araujo de (org.). Direito Sanitário: oportuna discussão via coletânea de textos do blog 'Direito Sanitário: saúde e cidadania', Brasília : ANVISA, CONASEMS, CONASS, 2012. p. 8590.

SANTOS, Lenir. Saúde: conceito e atribuições do Sistema Único de Saúde. 2005. [on line] Disponível em: http://jus.com.br/revista/texto/7378/saude-conceito-e-atribuicoes-do-sistemaunico-de-saude. Acesso em 08 jun. 2013.

SECRETARIA DE SAÚDE DO DISTRITO FEDERAL. SES e Defensoria Pública criam Câmara de Mediação em Saúde. 26 de fevereiro de 2013. [on line] Disponível em: http://www.saude.df.gov.br/noticias/item/2649-ses-e-defensoria-pública-criam-câmarade-mediação-em-saúde.html . Acesso em 16 jun. 2013.

SILVA, Vírgílio Afonso da. O Judiciário e as políticas públicas: entre transformação social e obstáculo à realização dos direitos sociais. In: SOUZA NETO, Cláudio Pereira de; SARMENTO, Daniel. Direitos sociais: fundamentação, judicialização e direitos sociais em espécies. Rio de Janeiro : Lumen Juris, 2008, p. 587-599.

VENTURA, Míriam, et al. Judicialização da saúde, acesso à justiça e a efetividade do 
direito à saúde. Physis Revista de Saúde Coletiva, Rio de Janeiro, 20(1):77-100, 2010.

VIEIRA, Fabíola Sulpino. Ações judiciais e direito à saúde: reflexão sobre a observância aos princípios do SUS. Revista Saúde Pública, 42(2):1-5, 2008.

VILAR, Silvia Barona. Las ADR en la justicia del siglo XXI, en especial la mediación. Revista de Derecho Universidad Católica del Norte, 18(1):185-211, 2011.

WATANABE, Kazuo. Política pública do poder Judiciário nacional para tratamento adequado dos conflitos de interesse. In: PELUSO, Antônio Cezar; RINHA, Morgana de Almeida (coord.). Conciliação e mediação: estruturação da política judiciária nacional. Rio de Janeiro : Forense, 2011. p. 3-9. 